\title{
INEX - A binary neuronal model with inhibitory and excitatory synapses
}

\author{
Kerstin Lenk ${ }^{*}$, Barbara Priwitzer \\ From Twentieth Annual Computational Neuroscience Meeting: CNS*2011 \\ Stockholm, Sweden. 23-28 July 2011
}

Our aim is to develop a simple model which is suitable to simulate concentration-response curves as observed in in-vitro experiments with multielectrode array (MEA) neurochips. In an in-vitro experiment approximately 10.000 neurons of the frontal cortex of embryonic mice [1] are cultivated on a MEA neurochip [2]. Neuro-active substances like bicuculline are added to the network. Based on the recorded data, various features [3] are calculated adapted from spikes and bursts. The features are separately displayed in concentration-response curves [4] which show the logarithm of the substance concentration and the chosen feature.

The developed INEX (inhibitory-excitatory) model is a cellular automaton whose cells are neurons with two possible states: ON or OFF. Each neuron obtains several inputs and produces exactly one output (respectively 0 or
1). Furthermore, it is phenomenological model where the neurons are described as black boxes. The probability if a spike occurs in time slice was calculated using a Poisson process [5]. Neurons are connected by either inhibitory or excitatory synapses with varying strength. The corresponding parameters are called weights. The network is fully connected and has direct feedbacks. Additionally, a spike time history was added. The aim was to vary the parameters of the model in such a way that we obtain a sigmoid concentration-response curve to simulate excitatory and inhibitory effects in neuronal networks.

A network with 100 neurons ran over 10 seconds with varying weights and $\Delta \mathrm{t}=1 \mathrm{~ms}$. Ninety inhibitory synapses with weights between -0.2 and 0 and ten excitatory synapses with weights between 0 and 0.7 are used. We detected spikes and bursts (figure 1) as known

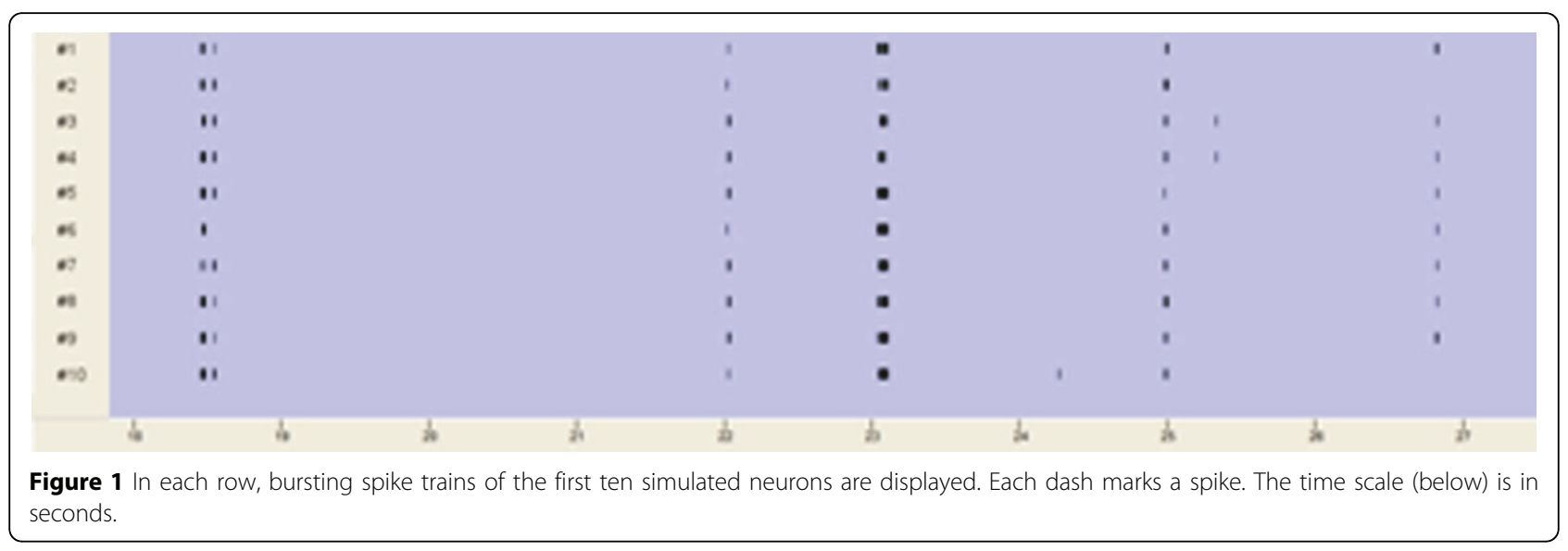

\footnotetext{
* Correspondence: kerstin.lenk@hs-lausitz.de

Department of Information Technology/ Electronics/ Mechanical Engineering, Lausitz University of Applied Sciences, Senftenberg, 01968 Germany
} 
from experiments with MEA neurochips. Thereafter, the same network ran over 18 minutes. The excitatory weights are reduced in six steps respectively by 0.05 every 3 minutes. The mean spike rate for each step is calculated and displayed in a concentration-response curve [6].

The INEX model shows potential to simulate inhibitory and excitatory effects which are also observed in experiments with MEA neurochips. A sigmoid concentration-response curve can be obtained by the simulation. We will work on parallelisation of processes to decrease the run time of the algorithm.

Published: 18 July 2011

\section{References}

1. Gramowski A, Juegelt K, Stuewe S, Schulze R, McGregor G, WartenbergDemand A, Loock J, Schroeder O, Weiss D: Functional screening of traditional antidepressants with primary cortical neuronal networks grown on multielectrode neurochips. Eur J Neurosci 2006, 24(2):455-465.

2. Gross GW, Rhoades BK, Azzazy HME, Wu MC: The use of neuronal networks on multielectrode arrays as biosensors. Biosensors \& Bioelectronics 1995, 10:553-567.

3. Schroeder OHU, Gramowski A, Jügelt K, Teichmann C, Weiss DG: Spike train data analysis of substance- specific network activity: Application to functional screening in preclinical drug development. 6th Int. Meeting on Substrate-Integrated Microelectrodes 2008.

4. Motulsky H, Christopoulos A: Fitting Models to Biological Data Using Linear and Nonlinear Regression: A Practical Guide to Curve Fitting. San Diego CA: GraphPad Software Inc.; 2003 [http://www.graphpad.com].

5. Heeger D: Poisson model of spike generation. 2000 [http://www.cns.nyu. edu/david/handouts/poisson.pdf]

6. Lenk K, Reuter M, Schroeder OHU, Gramowski A, Jügelt K, Priwitzer B: Information extraction from biphasic concentration-response curves for data obtained from neuronal activity of networks cultivated on multielectrode-array-neurochip. 19th Annual Computational Neuroscience Meeting San Antonio; 2010.

doi:10.1186/1471-2202-12-S1-P260

Cite this article as: Lenk and Priwitzer: INEX - A binary neuronal model with inhibitory and excitatory synapses. BMC Neuroscience 2011 12(Suppl 1):P260.

\section{Submit your next manuscript to BioMed Central and take full advantage of:}

- Convenient online submission

- Thorough peer review

- No space constraints or color figure charges

- Immediate publication on acceptance

- Inclusion in PubMed, CAS, Scopus and Google Scholar

- Research which is freely available for redistribution

Submit your manuscript at www.biomedcentral.com/submit 